\title{
Enhancing the Structural Strength for Injection Molding Tooling With Conformal Cooling Channels Using ANSYS Software
}

Chil-Chyuan Kuo ( $\nabla$ jacksonk@mail.mcut.edu.tw)

Ming Chi University of Technology https://orcid.org/0000-0003-0519-4126

Zheng-Yan You

Ming Chi University of Technology

\section{Research Article}

Keywords: Structural strength, Finite element method, Injection molding tooling, Metal additive manufacturing

Posted Date: April 9th, 2021

DOI: https://doi.org/10.21203/rs.3.rs-399879/v1

License: (c) (i) This work is licensed under a Creative Commons Attribution 4.0 International License.

Read Full License 


\section{Abstract}

Injection molding of wax patterns faces increasing demands for production rate. Proper thermal management of the injection molding tooling is capable of improving the production rate. Precise temperature control is a key to shorten the cooling time using the conformal cooling channels which are conformal to the molding cavity. However, the service life of the injection molding tooling with cooling channels will reduce significantly because the structural strength will reduce obviously. In this study, the feasibility of applying the increase in the mold thickness to maintain the structural strength of the injection molding tooling with cooling channels was verified through simulation and experiments conducted. It was found that the average variation between the results of simulation and the experiment is about $24.9 \%$. The approximately amount of the increase in the thickness required for different diameters of cooling channels can be determined according to the trend equation of $y=1.3429 x-2.3429$. The results can provide a reference for the conformal cooling channel design.

\section{Introduction}

In general, the cycle time is a main factor affecting the productivity in the mass production [1]. The cycle time in the injection molding process can be shortened by the use of conformal cooling channels because the cooling time takes most of the cycle time [2]. Li et al. [3] developed a topology optimization approach to design the conformal cooling system for injection molding and used the cycle-averaged approach to simplify the analysis of the cooling process during the design process. Two representative example models with areas that are hard to cool to test the effectiveness of the proposed optimization approach were investigated. It was found that the proposed method can improve both efficiency and uniformity of the cooling process. Vojnova [4] deals with the advantage of the molds with conformal cooling systems in the injection molding process. Results showed that the use of conforming cooling in the forms for plastic injection molding has a positive effect on shortening the production cycle and improving dimensional stability of the product. Mazur et al. [5] designed and manufactured a mould tool with easily exchangeable conformally cooled inserts and used a numerical simulation to evaluate an injection mold with conformal cooling system. Mechanical testing results showed the selective laser melting (SLM) components to offer lower mechanical properties in the as-built condition compared to conventional materials. The results of this work provide material property data for SLM manufactured $\mathrm{H} 13$ tooling with conformal cooling systems. Brooks and Brigden [6] introduced the concept of conformal cooling layers and proposed a concept for designing the conformal cooling layers with self-supporting lattices. A case study of the injection moulding of a plastic enclosure was employed to compare the performance of conformal cooling layers with that with conventional cooling channels and conformal cooling channels. It was found that the conformal layers reduce cooling time by $26.34 \%$ over conventional cooling channels. A mold with spherical spiral conformal cooling system for reducing the stress of the injection-molded polycarbonate was constructed by Wang et al. [7]. It was found that the service stress was affected significantly by the mold construction. In addition, the optimized mold and product design scheme are preferred to improve the service quality of the polycarbonate window. In order 
to reduce the time cost of the finite element analysis, Chen et al. [8] used the segmented finite element models to optimize the geometries of the cooling system. Results showed that very good agreement was obtained and the computational time saves up to $92.6 \%$ compared with the entire model of the U-shape component. Lim et al. [9] proposed a method for designing the cooling channel by triangular method for improving the strength and uniformity of hot stamped components. It was found that the reduction in the cooling time about $3 \mathrm{~s}$ was obtained. Armillotta et al. [10] fabricated the die-casting dies with conformal cooling by additive manufacturing technology. Experiments results showed that the conformal cooling improves the surface finish of cast parts. Additional advantages include the reduction of cycle time and shrinkage porosity. Holker and Tekkaya [11] fabricated the extrusion dies with conformal cooling channels to increase the productivity in hot aluminum extrusion. It was found that the hybrid tools withstand the high mechanical and thermal loads which occur during hot aluminum extrusion. However, the structural strength of the injection molding tooling with the conformal cooling channels will reduce significantly [12-15]. Figure 1 shows the schematic illustration of a cooling channel cell under high injection pressure. The molded parts tend to have flash or the injection molding tooling may cause huge deformation, micro cracks, or even breaking under high injection molding pressure in the injection molding process. In this study, an approach by increasing the mold thickness was proposed in this study. The amount of increase in mold thickness for different diameters of conformal cooling channels can be calculated using the ANSYS software $[16,17]$. The injection molds without or with different diameters of conformal cooling channels were fabricated and the flexural strength can be determined by the threepoint bending test. In order to verify the accuracy of the simulation results using the finite element method, three experimental runs were carried out using a three-point bending test. The flexural strength for the injection molding tooling with the increase of the mold thickness was compared with that for the injection molding tooling without cooling channels.

\section{Experimental Details}

In order to main the structural strength of the injection molding tooling with conformal cooling channels the same as the mold without, a method of increasing the mold thickness was proposed in this study. Figure 2 shows the research methodology of this study. The amount of increase in mold thickness for different diameters of conformal cooling channels can be calculated using the finite element method [18]. The material properties of the aluminum-filled epoxy resin such as Poisson's ratio and the Young's modulus were determined from the results of mechanical testing using a universal testing machine (Insight 5 SL, MTS system) [19]. In this study, the support frame of the bending test and injection molding tooling were integrated as a finite element analysis model. The analysis model was prepared using computer-aided design software. Hexagonal 3D quadratic stress elements, SOLID 95, were used for meshing the part. In order to reduce the analysis time and ensure the accuracy of the analysis results, the analysis model was split in half due to the symmetry of the analysis model. Figure 3 shows the schematic illustration of the analysis model in this study. Figure 4 shows the schematic illustration of the mesh model, boundary conditions, and applied force. The applied force was set in the location of the center of the injection molding tooling according to the test situation of the three-point bending test. The 
area of the red frame entitled a was selected and set the UX displacement at zero because only half analysis model was used in this study. In addition the area of the red frame entitled $b$ was selected and set the UX, UY, and UZ degrees of freedom at zero because the support frame of the bending test was fixed.

The master model, injection molding tooling with or without cooling channels, and cooling channels were designed by using the Pro/ENGINEER software. In this study, a curved lens with the dimensions of $87 \mathrm{~mm}$ in outer diameter and $2 \mathrm{~mm}$ in thickness was designed and fabricated as a master model for fabricating injection molding tooling with or without cooling channels. According to the design principle of conformal cooling channels [20], the diameter of the conformal cooling channels is chosen to be $8 \mathrm{~mm}, 9 \mathrm{~mm}$, or 10 $\mathrm{mm}$ when the wall thickness of the master model is $2 \mathrm{~mm}$. The center distance of the conformal cooling channels with respect to mold cavity is selected 1 to 1.5 times the diameter of the conformal cooling channels. The center distance between conformal cooling channel and conformal cooling channel is selected 1 to 2 times the diameter of the conformal cooling channels. Figure 5 shows the digital designs of conformal cooling channels with diameters of $8 \mathrm{~mm}, 9 \mathrm{~mm}$, and $10 \mathrm{~mm}$. The original conformal cooling channels were fabricated by using a three-dimensional printing machine (uPrint, Stratasys Inc.) because the original conformal cooling channels with complex geometries can be fabricated rapidly and easily [21, 22]. The solution prepared by alkaline detergent (1310-73-2, Sodium hydroxide) was used for removing the support materials to obtain the conformal cooling channels. The $\mathrm{pH}$ meter $(\mathrm{pH} 600)$ was used to evaluate the $\mathrm{pH}$ value. In this study, silicone rubber (KE-1310ST, Shin Etsu Inc.) was used as materials to fabricate an intermediary mold for fabricating wax pattern of conformal cooling channels.

In order to fabricate injection molding tooling without cooling channels, silicone rubber was first used to fabricate interim molds. An injection molding tooling without cooling channels can then be fabricated by pouring the mixture into the mold frame. The mixture is composed of new epoxy resin and recycled aluminum-filled epoxy resin powders in a weight ratio of 2: 1. A vacuum machine (F-600, Feiling) was used to eliminate air bubbles from the resulting mixture. In order to obtain the required mechanical properties, the fabricated injection molding tooling was cured at about $30^{\circ} \mathrm{C}$ for $24-48 \mathrm{~h}$ in an oven (DH400, Deng Yag Inc.). Figure 6 shows the process layouts for fabricating injection molding tooling without cooling channels. The wax was used as materials to fabricate conformal cooling channels because it can be removed easily from the wax injection molding tooling by water vapor. The wax pattern of the conformal cooling channels can be fabricated by a low-pressure wax injection machine $[23,24]$ (0660, W\&W Inc.). Figure 7 shows the process layouts for fabricating injection molding tooling with conformal cooling channels.

The length and width of the core and cavity inserts are both $150 \mathrm{~cm}$. The original thickness of both the core and cavity inserts is $30 \mathrm{~mm}$. The applied force required to destroy the mold without the cooling channels can be determined by the three-point bending test. Figure 8 shows the situation of the threepoint bending test [25]. The distance between support points is $80 \mathrm{~cm}$. The movement speed of the bending test punch is about $0.2 \mathrm{~mm} / \mathrm{s}$. 


\section{Results And Discussion}

Injection molding tooling with complex internal conformal cooling channels can be fabricated easily due to the process flexibility by the use of rapid tooling technology. Figure 9 shows the wax patterns of conformal cooling channels with diameters of $8 \mathrm{~mm}, 9 \mathrm{~mm}$, and $10 \mathrm{~mm}$. Figure 10 shows the injection molding tooling without cooling channels and with cooling channels having diameters of $8 \mathrm{~mm}, 9 \mathrm{~mm}$, and $10 \mathrm{~mm}$. The result reveals that the conformal cooling channels made of wax were removed thoroughly. However, the structural strength of the injection molding tooling with conformal cooling channels is inferior to that without cooling channels. Thus, maintaining the structural strength of the injection molding tooling with different conformal cooling channels is needed.

Figure 11 shows the breaking results of the injection molding tooling without cooling channels. The direction of the breaking is radially from the center of the injection molding tooling to the outer edge. The required force of mold breaking can be determined by the three-point bending test. The cavity insert causes breaking easily because the cavity insert was placed on the top and the core was placed below. According to the force, the flexural stress [26-28] can be calculated using a three-point bending formula. In this study, the required force of mold breaking is $11100 \mathrm{~N}$ and the flexural stress of the injection molding tooling without cooling channels is $2.44 \mathrm{MPa}$. In addition, the maximum stress of the injection molding tooling without cooling channels can be calculated using the finite element method, as shown in Figure 12. In this study, the maximum stress of the injection molding tooling without cooling channels is 45.7 MPa.

Figure 13 shows the amount of the increase in the mold thickness for the injection molding tooling with diameters of $8 \mathrm{~mm}, 9 \mathrm{~mm}$, and $10 \mathrm{~mm}$. In the case of the injection molding tooling with diameters of 8 $\mathrm{mm}$, the maximum stresses for the increase in the mold thickness of $1 \mathrm{~mm}, 2 \mathrm{~mm}, 3 \mathrm{~mm}, 4 \mathrm{~mm}, 5 \mathrm{~mm}, 6$ $\mathrm{mm}, 7 \mathrm{~mm}, 8 \mathrm{~mm}, 9 \mathrm{~mm}$, and $10 \mathrm{~mm}$ are $129.1 \mathrm{MPa}$, 88.43 MPa, 85.55 MPa, 63.41 MPa, 60.15 MPa, 59.9 $\mathrm{MPa}$, 55.7 MPa, 52.1 MPa, 43.7 MPa, and 37.46 MPa, respectively. Two phenomena can be found from these results. One is the maximum stress of the injection molding tooling can be reduced by increasing the thickness of the mold. The other is the maximum stress of the injection molding tooling is lower to that of the injection molding tooling without cooling channels when the amount of the increase in the mold thickness was increased to $9 \mathrm{~mm}$. The original thickness of the injection molding tooling without cooling channels is $30 \mathrm{~mm}$. Therefore, the thickness of the injection molding tooling with diameters of 8 $\mathrm{mm}$ was recommended to be $39 \mathrm{~mm}$. In the case of the injection molding tooling with diameters of $9 \mathrm{~mm}$, the maximum stresses for the increase in the mold thickness of $1 \mathrm{~mm}, 2 \mathrm{~mm}, 3 \mathrm{~mm}, 4 \mathrm{~mm}, 5 \mathrm{~mm}, 6 \mathrm{~mm}$, $7 \mathrm{~mm}, 8 \mathrm{~mm}, 9 \mathrm{~mm}$, and $10 \mathrm{~mm}$ are 174.7 MPa, 137.5 MPa, 103.1 MPa, 86.6 MPa, 70.3 MPa, 63 MPa, 59.2 MPa, 44.2 MPa, 40.6 MPa, and 32.8 MPa, respectively. The maximum stress of the injection molding tooling is only slightly lower to that of the injection molding tooling without cooling channels when the amount of the increase in the mold thickness was increased to $8 \mathrm{~mm}$. Considering the simulation error $[29,30]$, the thickness of the injection molding tooling with diameters of $9 \mathrm{~mm}$ was recommended to be $39 \mathrm{~mm}$. In the case of the injection molding tooling with diameters of $10 \mathrm{~mm}$, the maximum stresses for the increase in the mold thickness of $1 \mathrm{~mm}, 2 \mathrm{~mm}, 3 \mathrm{~mm}, 4 \mathrm{~mm}, 5 \mathrm{~mm}, 6 \mathrm{~mm}, 7 \mathrm{~mm}, 8 \mathrm{~mm}, 9 \mathrm{~mm}, 10$ 
$\mathrm{mm}$, and $11 \mathrm{~mm}$ are $300.1 \mathrm{MPa}$, 187.4 MPa, 167.1 MPa, 117.3 MPa, 92.6 MPa, 85.9 MPa, 76.1 MPa, 56.5 $\mathrm{MPa}$, 46.9 MPa, 43.2 MPa, and 37.7 MPa, respectively. The maximum stress of the injection molding tooling is only slightly lower to that of the injection molding tooling without cooling channels when the amount of the increase in the mold thickness was increased to $10 \mathrm{~mm}$. Considering the simulation error, the thickness of the injection molding tooling with diameters of $10 \mathrm{~mm}$ was recommended to be $41 \mathrm{~mm}$.

In order to verify the simulation results, a three-point bending test was carried out to investigate the actual flexural stress. The target flexural stress obtained form the injection molding tooling without cooling channels is $2.44 \mathrm{MPa}$. Figure 14 shows the breaking results of the injection molding tooling with diameters of $8 \mathrm{~mm}, 9 \mathrm{~mm}$, and $10 \mathrm{~mm}$. The actual flexural stress can be calculated using a three-point bending formula. These results were consistent with the expectation. In the case of the injection molding tooling with diameters of $8 \mathrm{~mm}$, the actual flexural stress is about $3 \mathrm{MPa}$, which is greater than the target flexural stress about $0.56 \mathrm{MPa}$. The variation is about $22.7 \%$ because the real amount of the increase in the mold thickness is between 8 and $9 \mathrm{~mm}$. In this study, the amount of the increase in the mold thickness of $9 \mathrm{~mm}$ was employed to fabricate the injection molding tooling. In the case of the injection molding tooling with diameters of $9 \mathrm{~mm}$, the actual flexural stress is about $3.08 \mathrm{MPa}$, which is greater than the target flexural stress about $0.64 \mathrm{MPa}$. The variation is about $26.1 \%$ because the real amount of the increase in the mold thickness is between 8 and $9 \mathrm{~mm}$. In this study, the amount of the increase in the mold thickness of $9 \mathrm{~mm}$ was employed to fabricate the injection molding tooling. In the case of the injection molding tooling with diameters of $10 \mathrm{~mm}$, the actual flexural stress is about $3.07 \mathrm{MPa}$, which is greater than the target flexural stress about $0.63 \mathrm{MPa}$. The variation is about $25.9 \%$ because the real amount of the increase in the mold thickness is between 10 and $11 \mathrm{~mm}$. In this study, the amount of the increase in the mold thickness of $11 \mathrm{~mm}$ was employed to fabricate the injection molding tooling. It is clear that the average variation between the results of simulation and the experiment is about $24.9 \%$

According to the above research data, the amounts of the increase in the mold thickness for injection molding tooling with diameters of $8 \mathrm{~mm}, 9 \mathrm{~mm}$, and $10 \mathrm{~mm}$ are $9 \mathrm{~mm}, 9 \mathrm{~mm}$, and $11 \mathrm{~mm}$, respectively. In order to make data more fully, the ANSYS software was continuously used. The amount of the increase in the mold thickness for injection molding tooling with a diameter of $12 \mathrm{~mm}$ is $14 \mathrm{~mm}$. In order to predict the amount of the increase in the mold thickness for different diameters of cooling channels, four data were used to establish the trend equation. Figure 15 shows the amount of the increase in the mold thickness as a function of different diameters of cooling channels. The $y=1.3429 x-2.3429$ is a trend equation [31] for predicting the amount of the increase in the mold thickness required for different diameters of cooling channels. The $x$ and $y$ in the trend equation represent the diameter of cooling channels and the amount of the increase in the mold thickness required, respectively. In general, the larger the correlation coefficient $R^{2}$ value [32], the better the degree of accuracy of the trend equation. As can be seen, the correlation coefficient $\mathrm{R}^{2}$ is 0.942 . This means the approximately amounts of the increase in the mold thickness required can be predicted from this trend equation. Thus, the approximately amounts of the increase in the mold thickness for diameters of cooling channels of $3 \mathrm{~mm}, 4 \mathrm{~mm}, 5 \mathrm{~mm}, 6 \mathrm{~mm}, 7 \mathrm{~mm}$, 
$11 \mathrm{~mm}$, and $13 \mathrm{~mm}$ are about $1.7 \mathrm{~mm}, 3 \mathrm{~mm}, 4.4 \mathrm{~mm}, 5.7 \mathrm{~mm}, 7.1 \mathrm{~mm}, 12.4 \mathrm{~mm}$, and $15.1 \mathrm{~mm}$, respectively.

According to the results described above, the findings of this study are very practical and can provide a reference for the design of molds or dies with conformal cooling channel, especially for the fabrication of the injection molding tooling with conformal cooling channels using the technologies such as atom diffusion additive manufacturing (ADAM), electron beam melting (EBM) [33], SLM [34], selective laser sintering (SLS) [35], diffusion bonding (DB) [36], direct metal deposition (DMD) [37], or direct metal laser sintering (DMLS) [38] because the fabrication costs is costly. The fabricated molds or dies can be employed in metal injection molding [39], rotational molding [40], centrifugal molding, thermoforming [41], transfer molding [42], and hot stamping [43], plastic injection molding [44], or blow molding [45]. In addition, injection molding tooling with conformal cooling channels fabricated by DMLS, ADAM, EBM, SLM, SLS, DB, or DMD employs a hybrid machining process that results in the coolant leaking from the connection locations. A distinct feature of this method is that the injection molding tooling with conformal cooling channels will not result in coolant leaking during injection molding because an injection molding tooling can be fabricated by one-process machining process. In addition, the cooling effectiveness of the injection molding tooling with conformal cooling channels is better than that with conventional straight-line cooling channels [46]. However, the layout of conformal cooling channels was not optimized in this study. Thus, optimization of the layout of conformal cooling channels using design of experiment method [47-49] or topology optimization method [50-53] is an important research issue. These issues are currently being investigated and the results will be presented in a later work.

\section{Conclusions}

The structural strength of the injection molding tooling with cooling channels will reduce significantly. In order to prolong the service life of the injection molding tooling with conformal cooling channels, maintaining the structural strength of the injection molding tooling with conformal cooling channels is an important issue in the advanced mold or die manufacturing industry. The aim of this study is to improve structural strength for the injection molding tooling with conformal cooling channels the same as that of the injection molding tooling without conformal cooling channels by adjusting the thickness of the injection molding tooling. The amount of increase in mold thickness required can be determined using the ANSYS software. Based on the results discussed in this study, the following conclusions can be drawn:

1. The results are very practical and provide the greatest application potential for the injection molding tooling with conformal cooling channels fabricated by metal additive manufacturing technology.

2. The structural strength of the injection molding tooling can be enhanced by increasing the thickness of the injection molding tooling determined by the ANSYS software.

3. The actual flexural stress can be determined through three-point bending test. The average variation between the results of simulation and the experiment is about $24.9 \%$. 
4. The approximately amount of the increase in the mold thickness required for different diameters of cooling channels can be determined according to the trend equation of $y=1.3429 x-2.3429$.

\section{Declarations}

\section{Funding :}

This study received financial support by the Ministry of Science and Technology of Taiwan under contract number MOST 109-2637-E-131-004.

Conflicts of interest/Competing interests :Not applicable

Availability of data and material $₫ \mathrm{D}$ ata and materials are available

Code availability $\llbracket$ Not applicable

\section{Authors' contributions $]$}

Arthur 1『Chil-Chyuan Kuo खWrote the paper/ Conceived and designed the analysis/ Performed the analysis

Arthur 2『Zheng-Yan You囚Collected the data/Contributed data or analysis tools

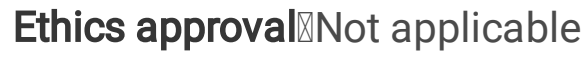

Consent to participate $\mathbb{\|}$ am agreeing to participate

Consent for publication邓I am agreeing to publish this work

\section{References}

1. M.Nilakantan, I. Nielsen, S. G. Ponnambalam, S. Venkataramanaiah," Differential evolution algorithm for solving RALB problem using cost- and time-based models," The International Journal of Advanced Manufacturing Technology, Volume 89, Issue 1-4, 2017, Pages 311-332.

2. Kitayama, H. Miyakawa, M.Takano, S. Aiba," Multi-objective optimization of injection molding process parameters for short cycle time and warpage reduction using conformal cooling channel," The International Journal of Advanced Manufacturing Technology, Volume 88, Issue 5-8, 2017, Pages 1735-1744.

3. Li, X. Wang, J. Gu, S. Ruan, C. Shen, Y. Lyu, Y. Zhao," Topology Optimization for the Design of Conformal Cooling System in Thin-wall Injection Molding Based on BEM," The International Journal of Advanced Manufacturing Technology, The International Journal of Advanced Manufacturing Technology, Volume 94, Issue 1-4, 2018, Pages 1041-1059.

4. Eva Vojnová," The Benefits of a Conforming Cooling Systems the Molds in Injection Moulding Process," Procedia Engineering, Volume 149, 2016, Pages 535-543. 
5. Mazur, P. Brincat, M. Leary, M. Brandt," Numerical and experimental evaluation of a conformally cooled H13 steel injection mould manufactured with selective laser melting," The International Journal of Advanced Manufacturing Technology, Volume 93, Issue 1-4, 2017, Page 881-900.

6. Brooks and K. Brigden," Design of conformal cooling layers with self-supporting lattices for additively manufactured tooling," Additive Manufacturing, Volume 11, 2016, Pages 16-22.

7. Wang, Z. Li, J. Gu, S. Ruan, C. Shen, X. Wang," Reducing service stress of the injection-molded polycarbonate window by optimizing mold construction and product structure," The International Journal of Advanced Manufacturing Technology, Volume 86, Issue 5-8, 2016, Pages 1691-1704.

8. Chen, P. Gong, Y. Liu, X. Zheng, F. Ren," Optimization of hot stamping cooling system using segmented model," The International Journal of Advanced Manufacturing Technology, Volume 93, Issue 1-4, 2017, Pages 1357-1365.

9. S. Lim, H. S. Choi, S. Y. Ahn, B. M. Kim," Cooling channel design of hot stamping tools for uniform high-strength components in hot stamping process," The International Journal of Advanced Manufacturing Technology, Volume 70, Issue 5-8, 2014, Pages 1189-1203.

10. Armillotta, R. Baraggi, S. Fasoli," SLM tooling for die casting with conformal cooling channels," The International Journal of Advanced Manufacturing Technology, Volume 71, Issue 1-4, 2014, Pages 573-583.

11. Holker and A. E. Tekkaya," Advancements in the manufacturing of dies for hot aluminum extrusion with conformal cooling channels," The International Journal of Advanced Manufacturing Technology, Volume 83, Issue 5-8, 2016, Pages 1209-1220.

12. C. Kuo, B. C. Chen, "Development of hot embossing stamps with conformal cooling channels for microreplication," The International Journal of Advanced Manufacturing Technology,Volume 88, Issue 9, 2017, Pages 2603-2608.

13. C. Kuo, W. H. Chen, X. Z. Liu, Y. L. Liao, W. J. Chen, B. Y. Huang, R. L. Tsai," Development of a low-cost wax injection mold with high cooling efficiency," The International Journal of Advanced Manufacturing Technology, Volume 93, Issue 5-8, 2017, Pages 2081-2088.

14. C. Kuo, W. H. Chen, J. W. Zhang, D. A. Tsai, Y. L. Cao, "A new method of manufacturing a rapid tooling with different cross-sectional cooling channels," Thelnternational Journal of Advanced Manufacturing Technology, Volume 92, Issue 9-12, 2017, Pages 3481-3487.

15. C. Kuo, W. H. Chen, W. C. Xu, "A cost-effective approach for rapid manufacturing wax injection molds with complex geometrical shapes of cooling channels," The International Journal of Advanced Manufacturing Technology, Volume 91, Issue 5-8, 2017, Pages 1689-1695.

16. Langford, E.; Griffiths, C.A.; Rees, A.; Bird, J. The Micro Topology and Statistical Analysis of the Forces of Walking and Failure of an ITAP in a Femur. Micromachines 2021, 12, 298.

17. Wang G, Wang Y, Lv B, Ma R, Liu L. Research on a New Type of Rigid-Flexible Coupling 3-DOF MicroPositioning Platform. Micromachines. 2020; 11(11):1015.

18. Belhocine, W. Z. W. Omar," Three-dimensional finite element modeling and analysis of the mechanical behavior of dry contact slipping between the disc and the brake pads," The International 
Journal of Advanced Manufacturing Technology, Volume 88, Issue 1-4, 2017, Pages 1035-1051.

19. C. Kuo, S. Y. Lyu, "A cost-effective approach using recycled materials to fabricate micro-hot embossing die for microfabrication," The International Journal of Advanced Manufacturing Technology, Volume 94, Issue 9-12, 2018, Pages 4365-4371.

20. M. Au and K. M. Yu," Conformal cooling channel design and CAE simulation for rapid blow mould," The International Journal of Advanced Manufacturing Technology, Volume 66, Issue 1-4, 2013, Pages 311-324.

21. Nakagawa, K. I. Mori, T. Maeno," 3D printing of carbon fibre-reinforced plastic parts," he International Journal of Advanced Manufacturing Technology, Volume 91, Issue 5-8, 2017, Pages 2811-2817.

22. Do," Integration of design and manufacturing data to support personal manufacturing based on 3D printing services," The International Journal of Advanced Manufacturing Technology, Volume 90, Issue 9-12, 2017, Pages 3761-3773.

23. Wang, D., Sun, J., Dong, A. et al. Prediction of core deflection in wax injection for investment casting by using SVM and BPNN. Int J Adv Manuf Technol 101, 2165-2173 (2019).

24. Almonti, D., Baiocco, G., Mingione, E. et al. Evaluation of the effects of the metal foams geometrical features on thermal and fluid-dynamical behavior in forced convection. Int $\mathrm{J}$ Adv Manuf Technol 111, 1157-1172 (2020).

25. Cornelissen, R., Maljaars, J. \& Hofmeyer, H. Buckling and wrinkling of rectangular hollow sections curved in three-point-roll bending. Int J Adv Manuf Technol 112, 2091-2107.

26. Bensalah, H., Raji, M., Abdellaoui, H. et al. Thermo-mechanical properties of low-cost "green" phenolic resin composites reinforced with surface modified coir fiber. Int J Adv Manuf Technol 112, 19171930 (2021).

27. Verma, P., Ubaid, J., Schiffer, A. et al. Essential work of fracture assessment of acrylonitrile butadiene styrene (ABS) processed via fused filament fabrication additive manufacturing. Int J Adv Manuf Technol (2021).

28. Liang, J., Liang, T., Li, Y. et al. Novel flexible cores in rotary draw bending forming: applied for the commercial vehicle anti-collision beam with rectangular ribbed (囚-shaped) section. Int J Adv Manuf Technol 112, 1545-1556 (2021).

29. Pour, H. Ghorbani," Improving FEM model of low immersion milling process using multi-objective optimization of tool elastic support dynamic properties," The International Journal of Advanced Manufacturing Technology, Volume 92, Issue 5-8, 2017, Pages 2279-2297.

30. Clement, J. L. Huang, Z. H. Sun, J. Z. Wang, W. J. Zhang," Motion and stress analysis of direct-driven compliant mechanisms with general-purpose finite element software," The International Journal of Advanced Manufacturing Technology, Volume 65, Issue 9-12, 2013, Pages 1409-1421.

31. Scharowsky, A. Bauereib, C. Korner," Influence of the hatching strategy on consolidation during selective electron beam melting of Ti-6Al-4V," The International Journal of Advanced Manufacturing Technology, Volume 92, Issue 5-8, 2017, Pages 2809-2818. 
32. Liu, Y. Yang, D. Wang, " A study on the residual stress during selective laser melting (SLM) of metallic powder," The International Journal of Advanced Manufacturing Technology, Volume 87, Issue 1-4, 2016, Pages 647-656.

33. L. Leite, G. V. Salmoria, R. A. Paggi, C. H. Ahrens, A. S. Pouzada, "Microstructural characterization and mechanical properties of functionally graded PA12/HDPE parts by selective laser sintering," The International Journal of Advanced Manufacturing Technology, Volume 59, Issue 5-8, 2012, Pages 583-591.

34. Yan, Y., Zhang, Z., Zhao, B. et al. Study on prediction of three-dimensional surface roughness of nano-ZrO2 ceramics under two-dimensional ultrasonic-assisted grinding. Int J Adv Manuf Technol 112, 2623-2638 (2021)

35. Niu, P., Cheng, Q., Liu, Z. et al. A machining accuracy improvement approach for a horizontal machining center based on analysis of geometric error characteristics. Int J Adv Manuf Technol 112, 2873-2887 (2021).

36. Lin, H. Luo, W. Huang, X. Zhang, G. Yao," Diffusion bonding in fabrication of aluminum foam sandwich panels," Journal of Materials Processing Technology, Volume 230, 2016, Pages 35-41.

37. I. Gorunov and A. Kh. Gilmutdinov," Study of the effect of heat treatment on the structure and properties of the specimens obtained by the method of direct metal deposition," The International Journal of Advanced Manufacturing Technology, Volume 86, Issue 9-12, 2016,Pages 2567-2574.

38. AlMangour and J. M. Yang," Understanding the deformation behavior of 17-4 precipitate hardenable stainless steel produced by direct metal laser sintering using micropillar compression and TEM," The International Journal of Advanced Manufacturing Technology, Volume 90, Issue 1-4, 2017, Pages 119-126.

39. Safarian, M.Subaşi, Ç. Karataş," The effect of sintering parameters on diffusion bonding of 316L stainless steel in inserted metal injection molding," The International Journal of Advanced Manufacturing Technology, 2017, Volume 89, Issue 5-8, Pages 2165-2173.

40. Lucas, A., Danlos, A., Shirinbayan, M. et al. Conventional rotational molding process and aerodynamic characteristics of an axial-flow hollow blades rotor. Int J Adv Manuf Technol 104, 1183-1194 (2019).

41. Redaelli, D.F., Abbate, V., Storm, F.A. et al. 3D printing orthopedic scoliosis braces: a test comparing FDM with thermoforming. Int J Adv Manuf Technol 111, 1707-1720 (2020).

42. Aaboud, B., Saouab, A. \& Park, C.H. Modeling of air bubble dynamics during resin transfer molding by pore doublet model. Int J Adv Manuf Technol 105, 2343-2355 (2019).

43. Cortina , ID , J. I. Arrizubieta, A. Calleja, E. Ukar, A. Alberdi," Case Study to Illustrate the Potential of Conformal Cooling Channels for Hot Stamping Dies Manufactured Using Hybrid Process of Laser Metal Deposition (LMD) and Milling," Metals, 2018, Volume 8, Issue 102, Pages 1-15.

44. Krebelj, M. Halilovič, N. Mole," The cooling rate dependence of the specific volume in amorphous plastic injection molding," The International Journal of Advanced Manufacturing Technology, 2019, Volume 103, Issue 1-4, Pages 1175-1184. 
45. Li, Q. Lan, D. Dong, Z. Liu, Z. Li, Y. Bian," Integrated design and process analysis of a blow molding turbo-charged pipe," The International Journal of Advanced Manufacturing Technology, 2014, Volume 73, Issue 1-4, Pages 63-72.

46. Liu, C., Cai, Z., Dai, Y. et al. Experimental comparison of the flow rate and cooling performance of internal cooling channels fabricated via selective laser melting and conventional drilling process. Int J Adv Manuf Technol 96, 2757-2767 (2018).

47. You, K.; Fang, F.; Yan, G.; Zhang, Y. Experimental Investigation on Laser Assisted Diamond Turning of Binderless Tungsten Carbide by In-Process Heating. Micromachines2020, 11, 1104.

48. Le Coz, G., Piquard, R., D'Acunto, A. et al. Precision turning analysis of Ti-6Al-4V skin produced by selective laser melting using a design of experiment approach. Int J Adv Manuf Technol 110, 16151625 (2020).

49. Kuo, CC., Yang, XY. Optimization of direct metal printing process parameters for plastic injection mold with both gas permeability and mechanical properties using design of experiments approach. Int J Adv Manuf Technol 109, 1219-1235 (2020).

50. Langford, E.; Griffiths, C.A.; Rees, A.; Bird, J. The Micro Topology and Statistical Analysis of the Forces of Walking and Failure of an ITAP in a Femur. Micromachines 2021, 12, 298.

51. Park, J.; Zobaer, T.; Sutradhar, A. A Two-Scale Multi-Resolution Topologically Optimized MultiMaterial Design of 3D Printed Craniofacial Bone Implants. Micromachines2021, 12, 101

52. Xu, S.; Huang, J.; Liu, J.; Ma, Y. Topology Optimization for FDM Parts Considering the Hybrid Deposition Path Pattern. Micromachines 2020, 11, 709.

53. Guo, Y.; Pan, H.; Wadbro, E.; Liu, Z. Design Applicable 3D Microfluidic Functional Units Using 2D Topology Optimization with Length Scale Constraints. Micromachines2020, 11, 613.

\section{Figures}


Mold surface profile under

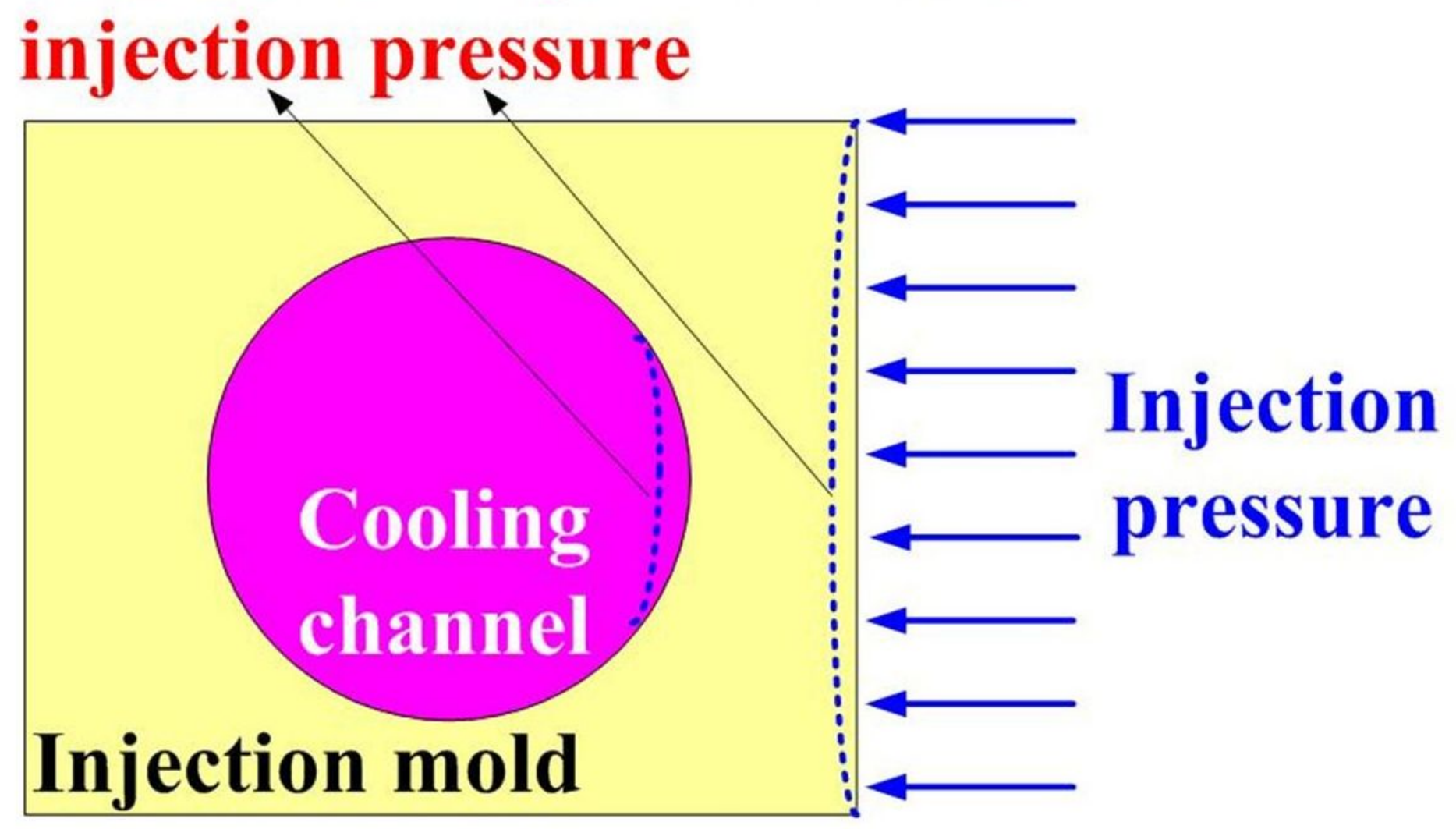

Figure 1

Schematic illustration of a cooling channel cell under high injection pressure 


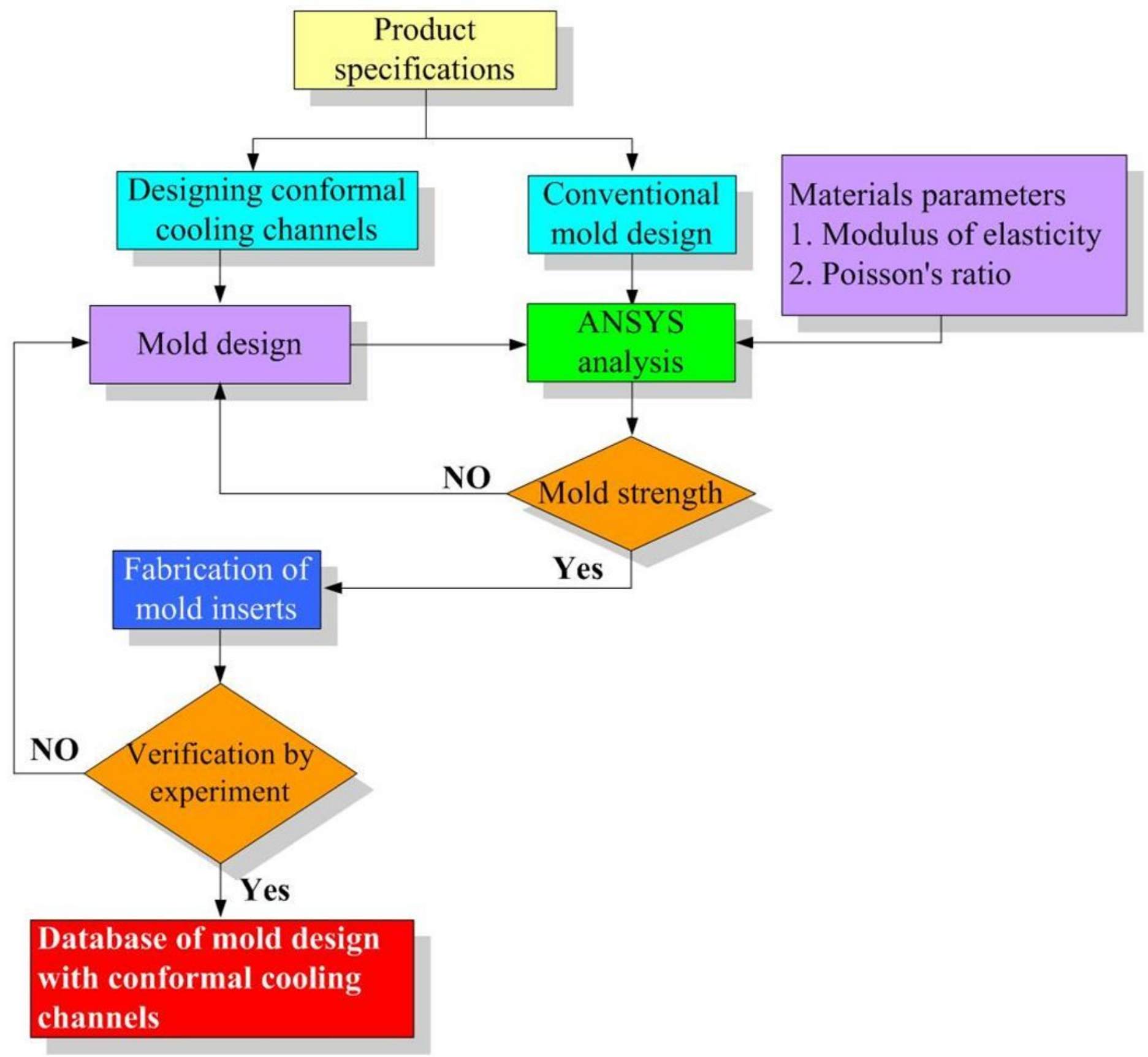

Figure 2

Research methodology of this study 

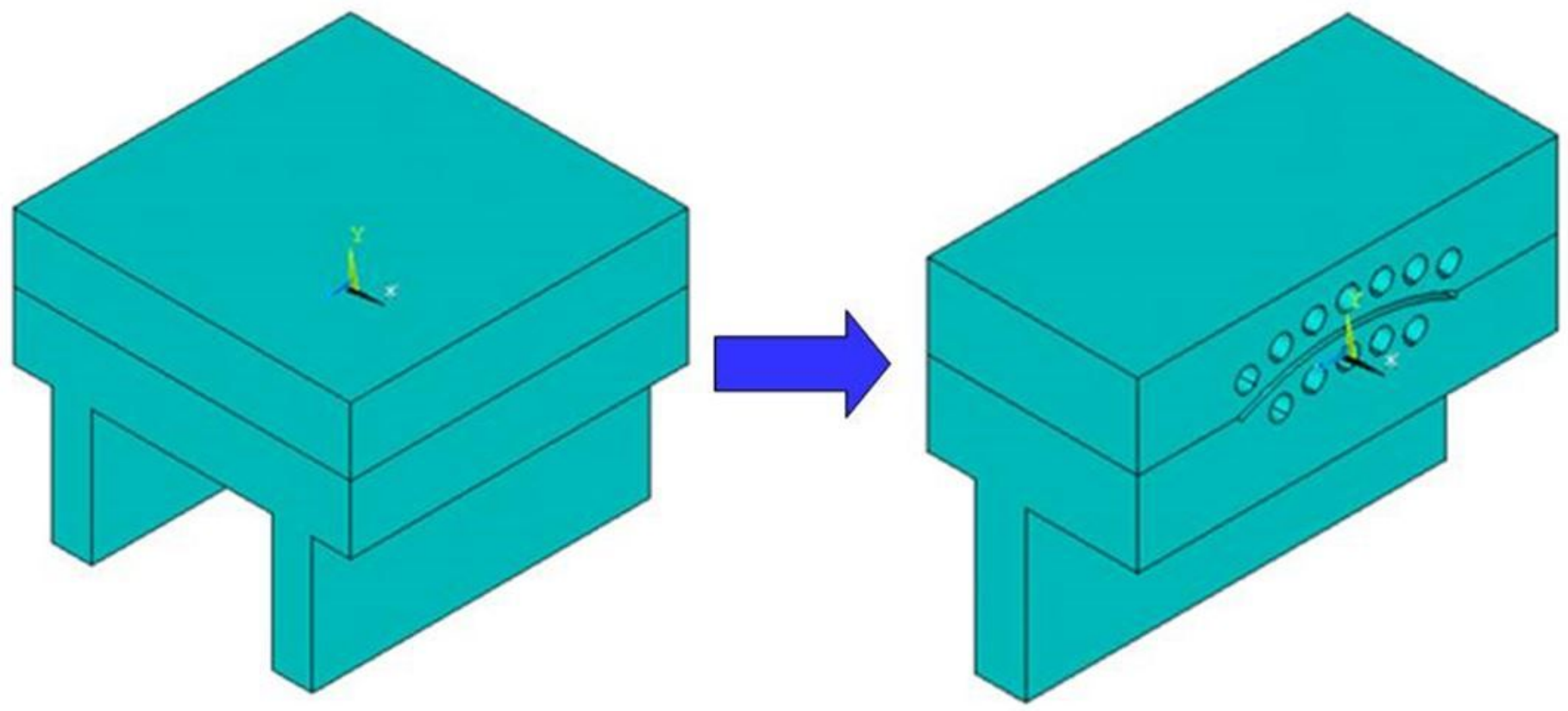

Figure 3

Schematic illustration of the analysis model in this study
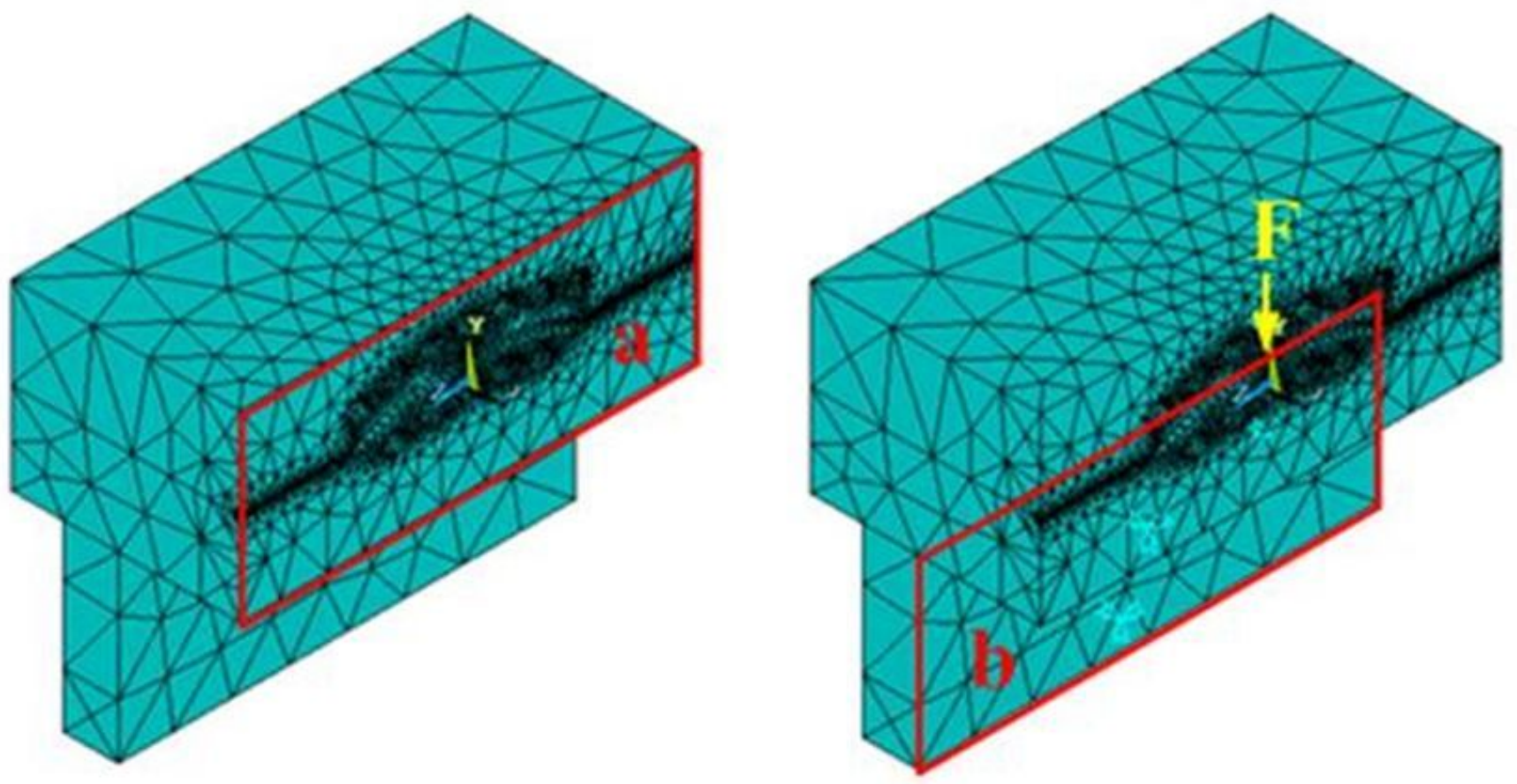

Figure 4

Schematic illustration of the mesh model, boundary conditions, and applied force 
(a)
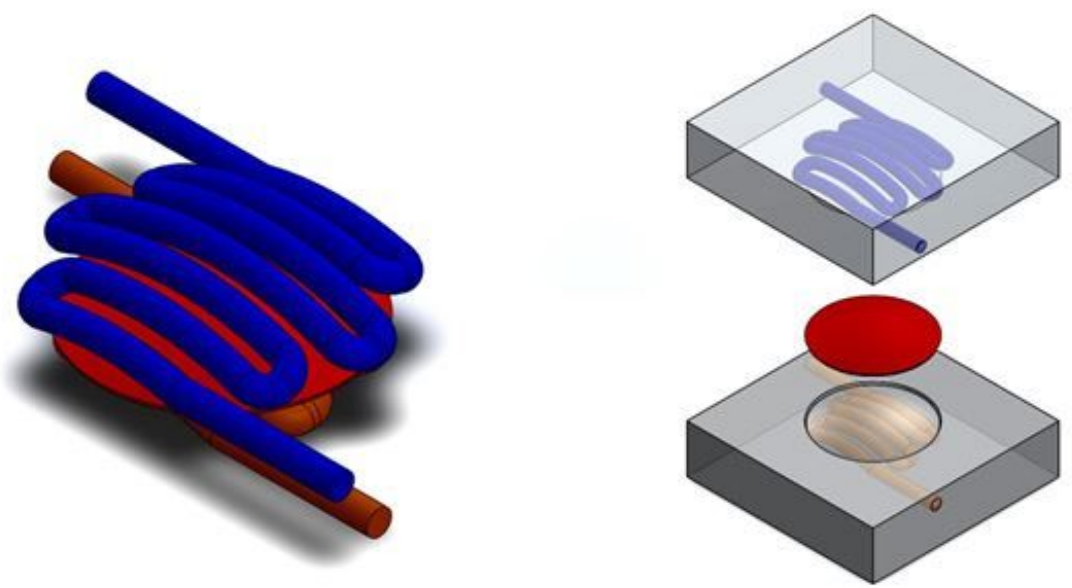

(b)
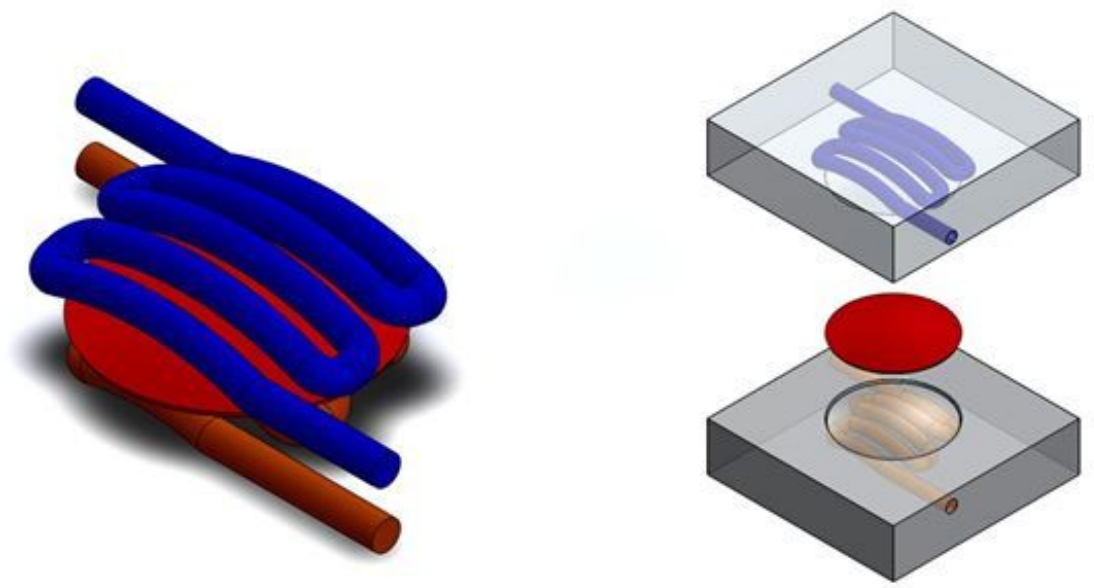

(c)
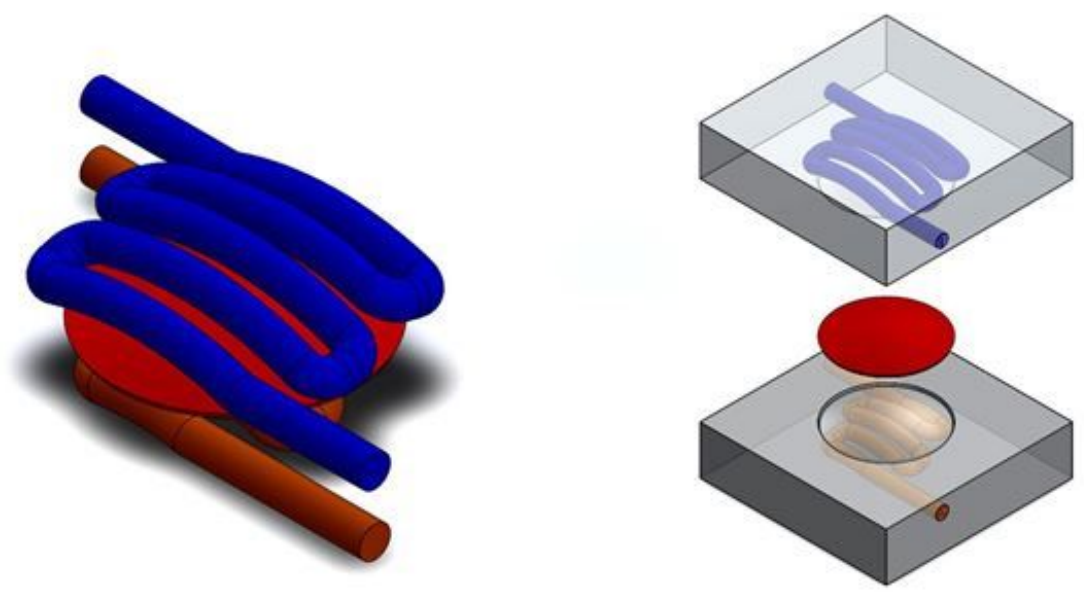

Figure 5

Digital designs of conformal cooling channels with diameters of (a) $8 \mathrm{~mm}$, (b) $9 \mathrm{~mm}$, and (c) $10 \mathrm{~mm}$ 


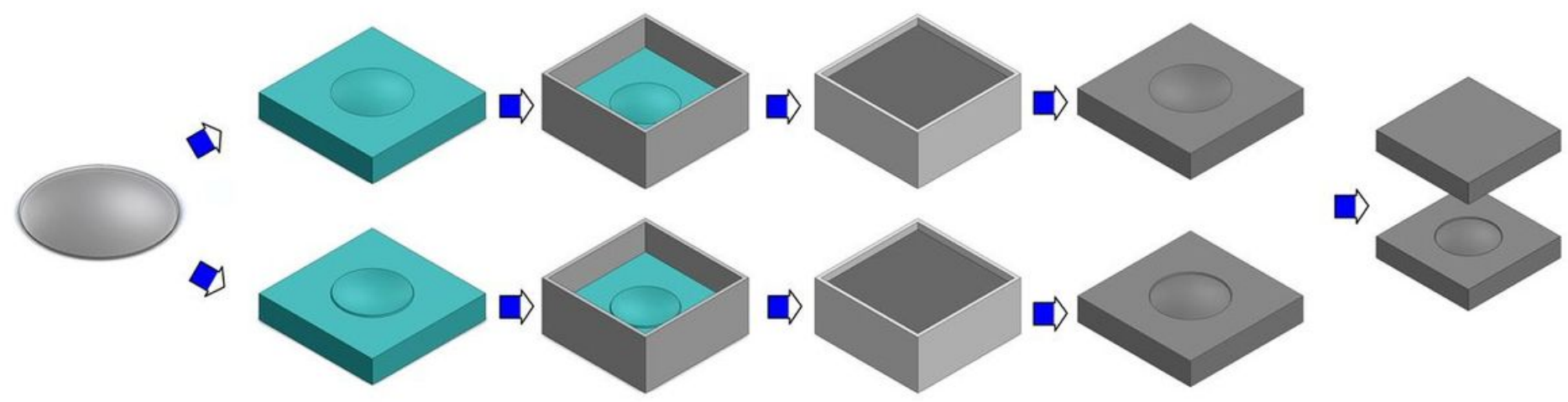

Figure 6

Process layouts for fabricating injection molding tooling without cooling channels
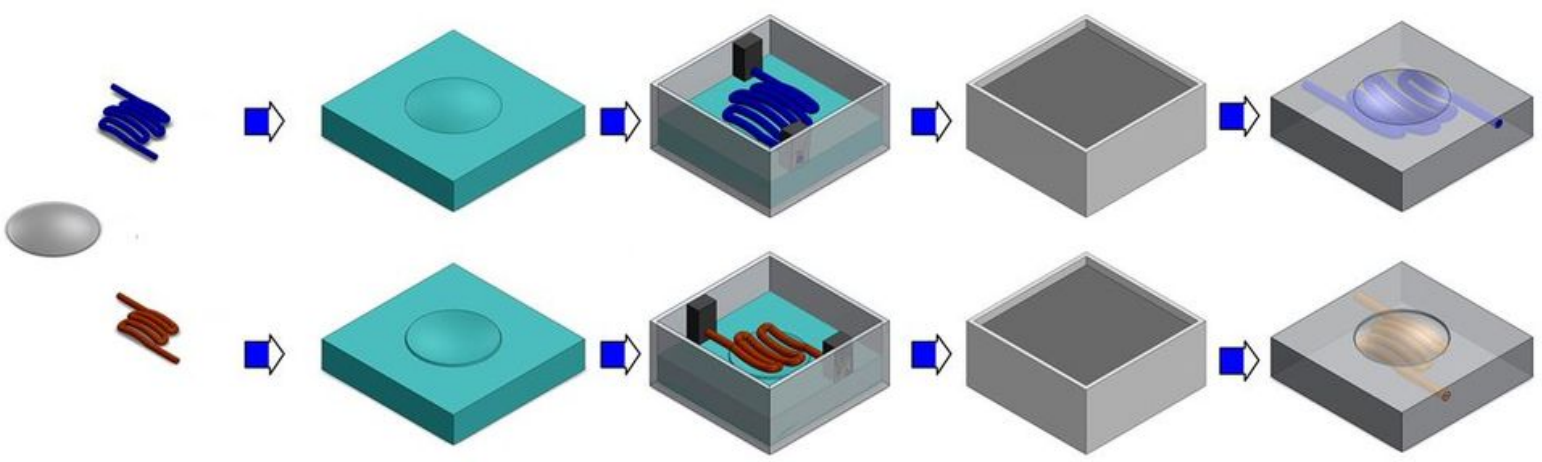

\section{Figure 7}

Process layouts for fabricating injection molding tooling with conformal cooling channels 


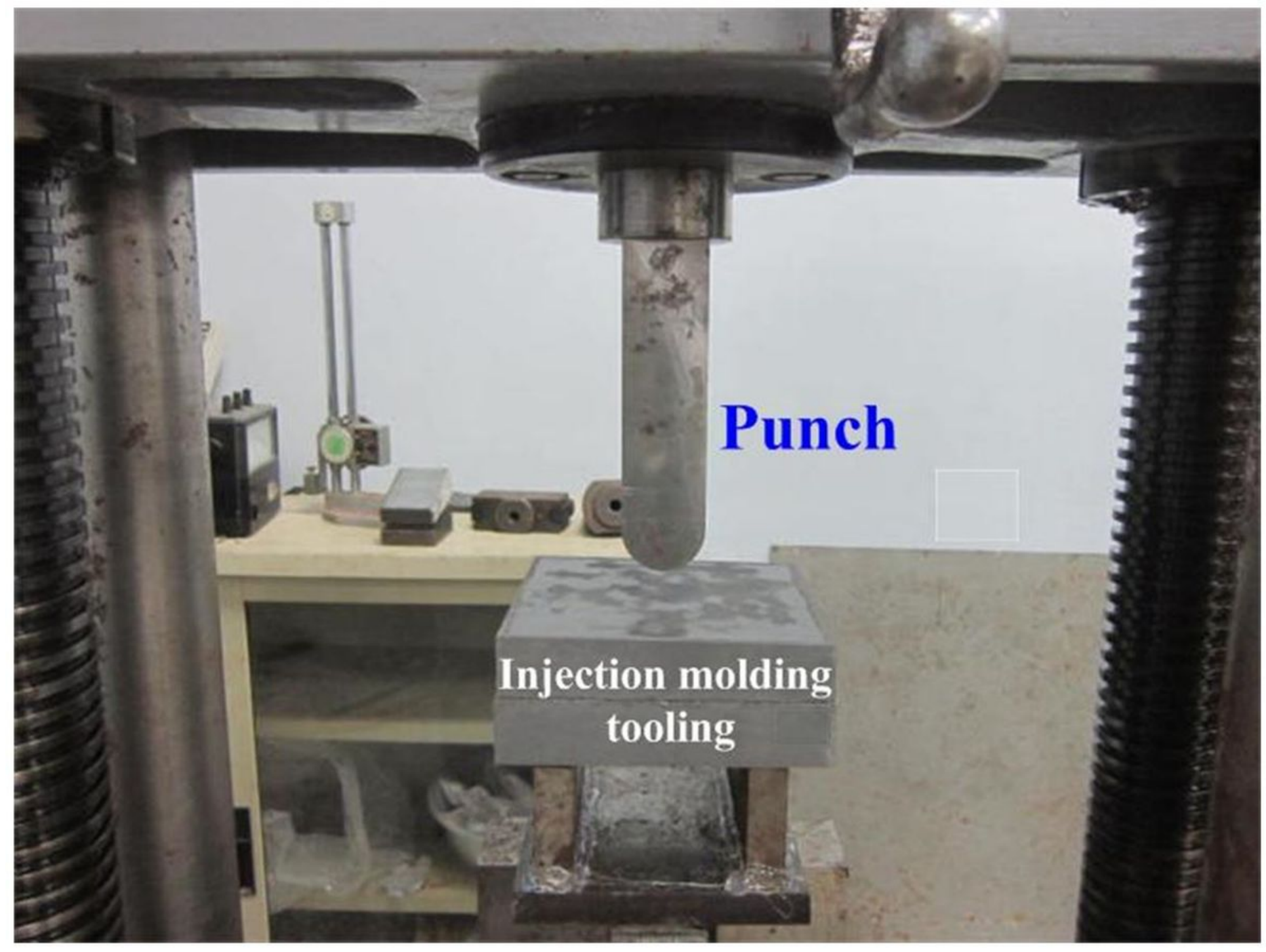

Figure 8

Situation of the three-point bending test 


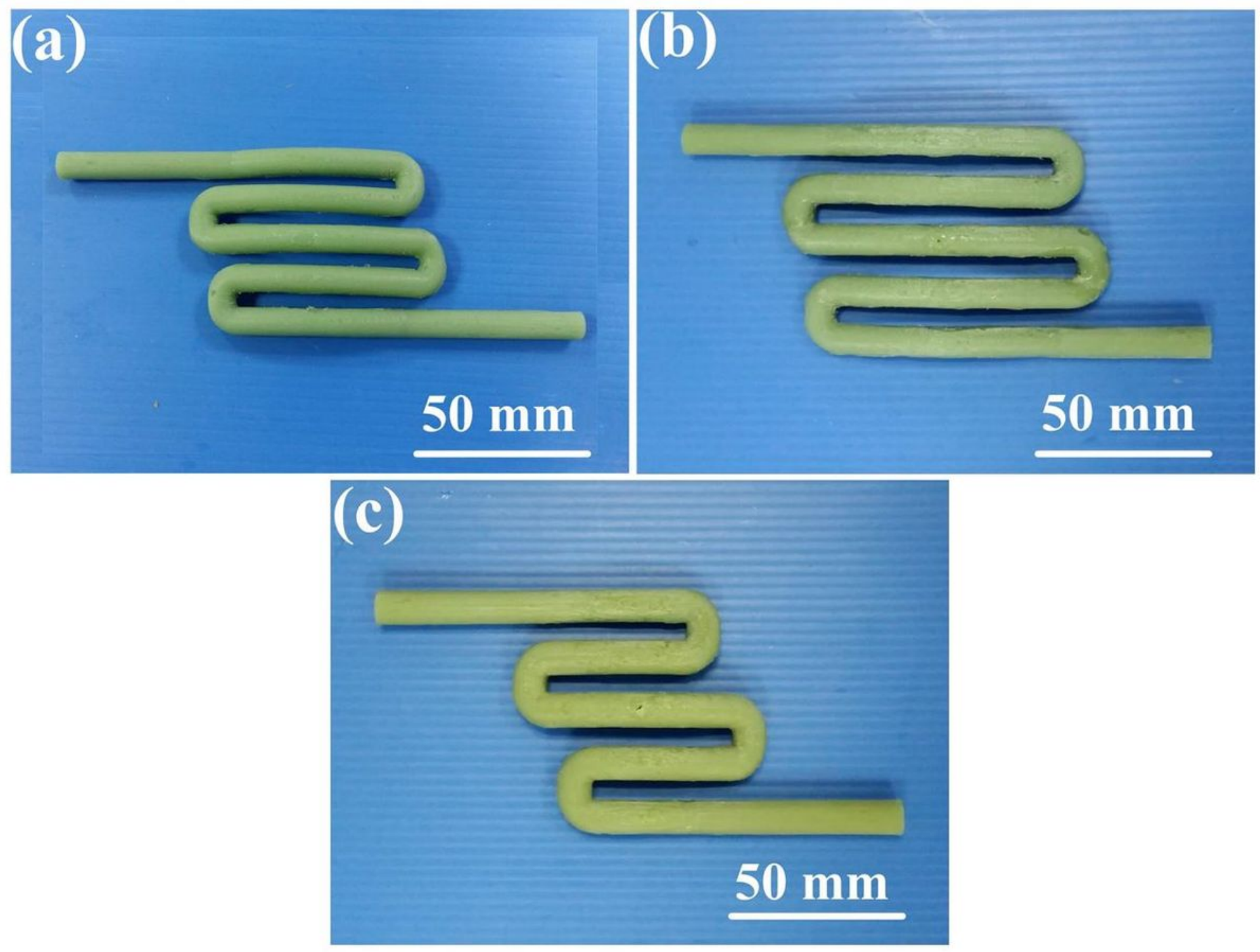

Figure 9

Wax patterns of conformal cooling channels with diameters of (a) $8 \mathrm{~mm}$, (b) $9 \mathrm{~mm}$, and (c) $10 \mathrm{~mm}$ 


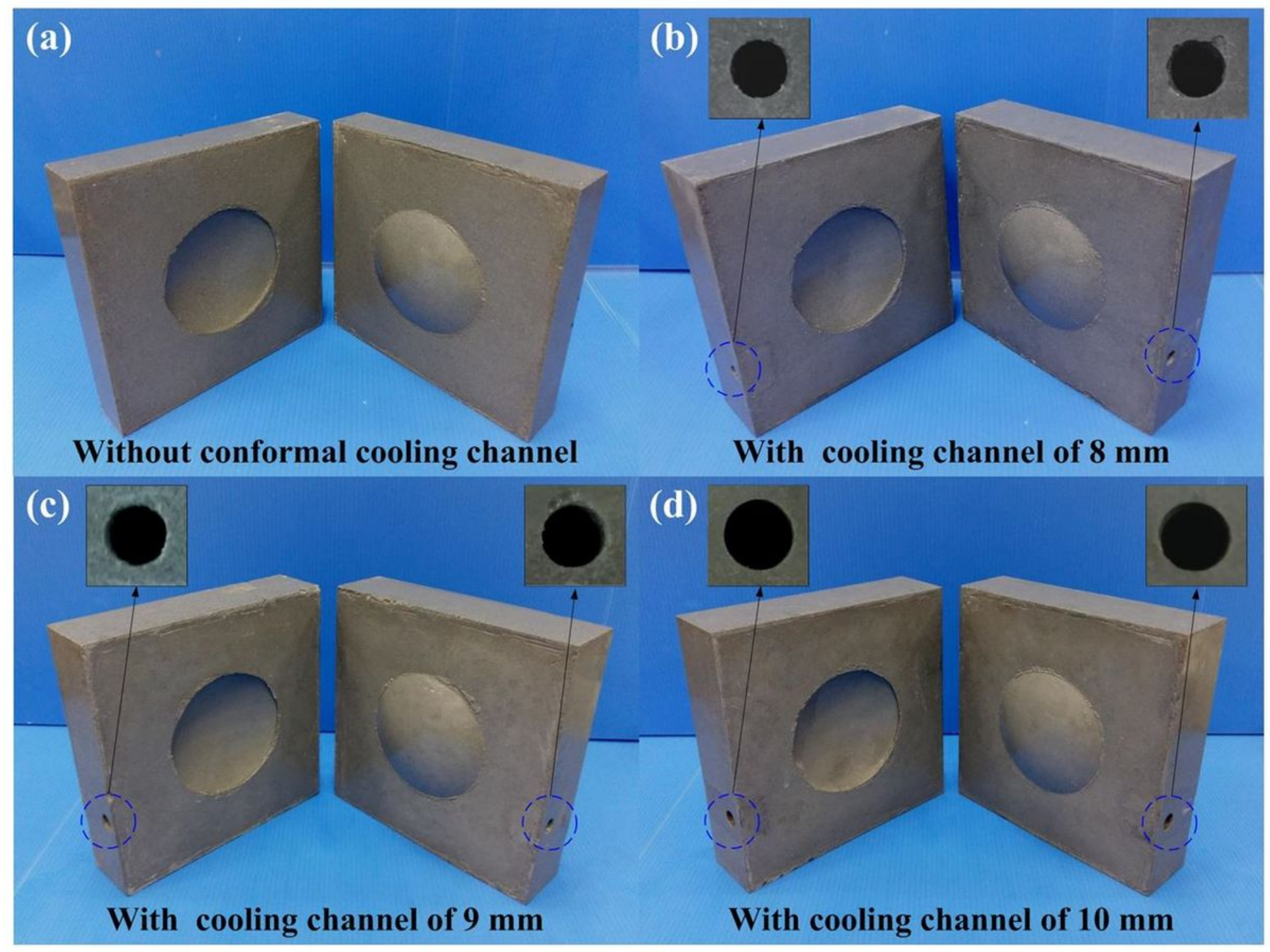

\section{Figure 10}

Injection molding tooling (a) without cooling channels and with cooling channels having diameters of (b) $8 \mathrm{~mm},(\mathrm{c}) 9 \mathrm{~mm}$, and (d) $10 \mathrm{~mm}$ 


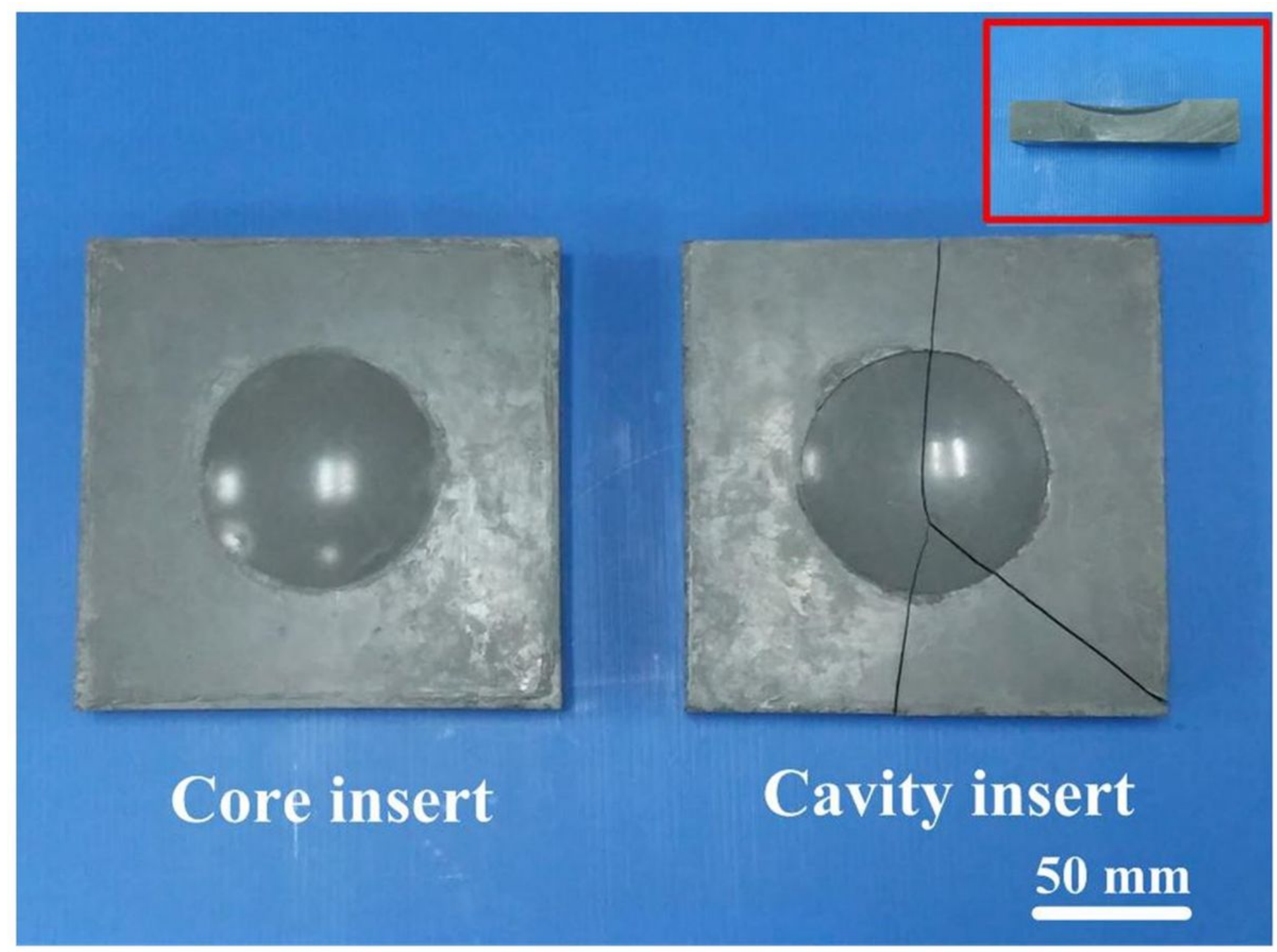

Figure 11

Breaking result of the injection molding tooling without cooling channels 

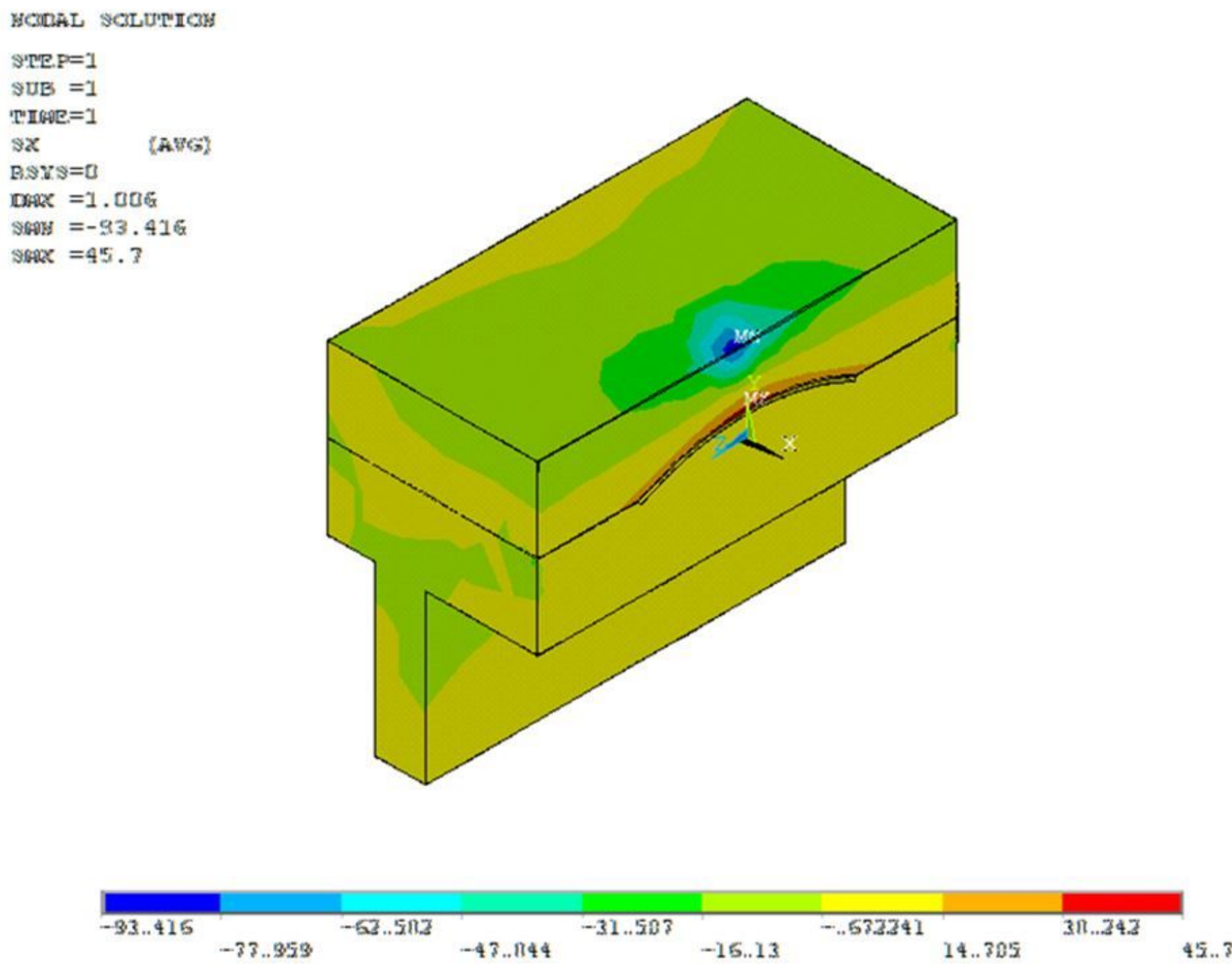

Figure 12

Maximum stress of the injection molding tooling without cooling channels 

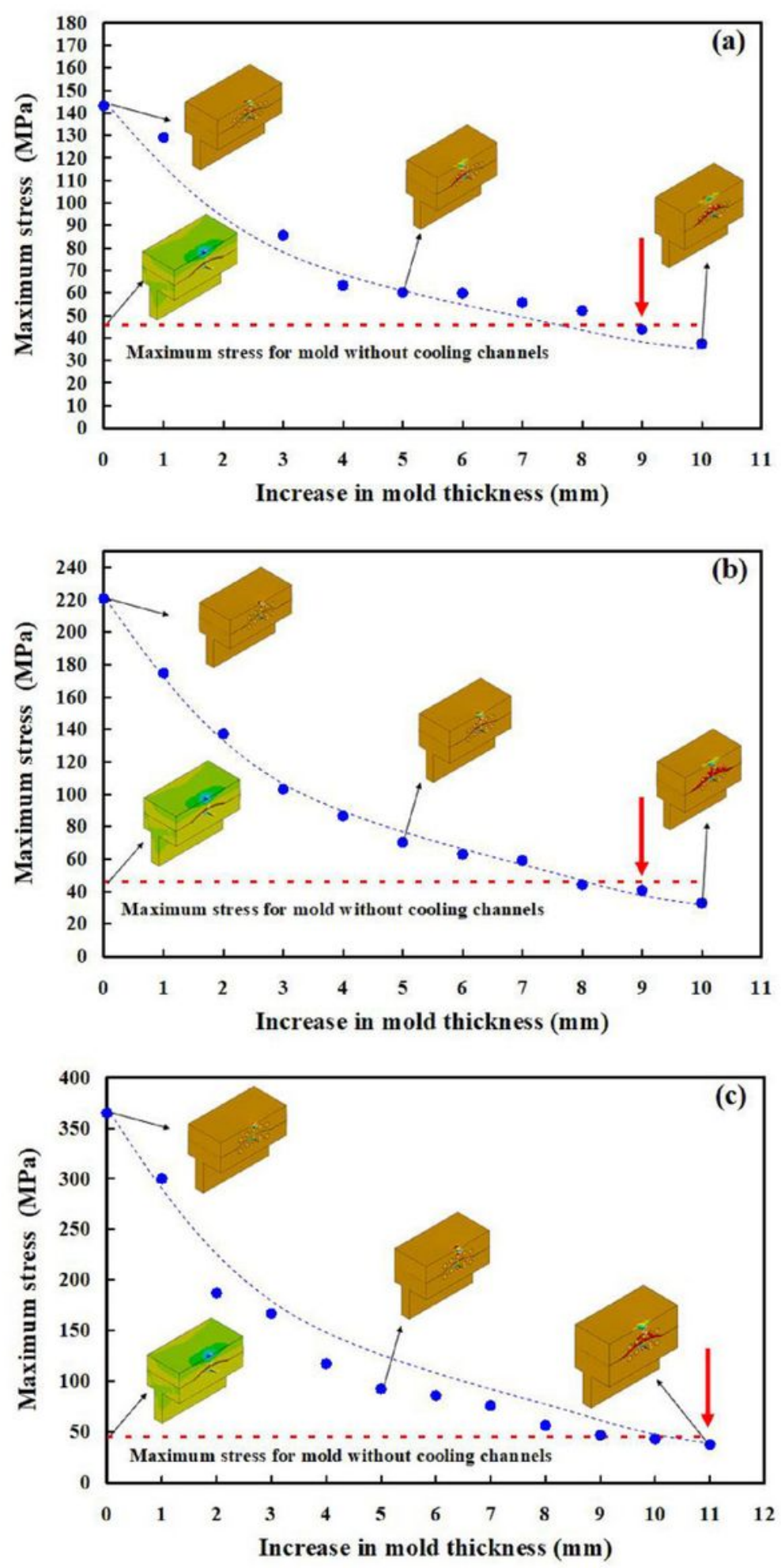

\section{Figure 13}

The amount of the increase in the mold thickness for injection molding tooling with diameters of (a) 8 $\mathrm{mm}$, (b) $9 \mathrm{~mm}$, and (c) $10 \mathrm{~mm}$ 


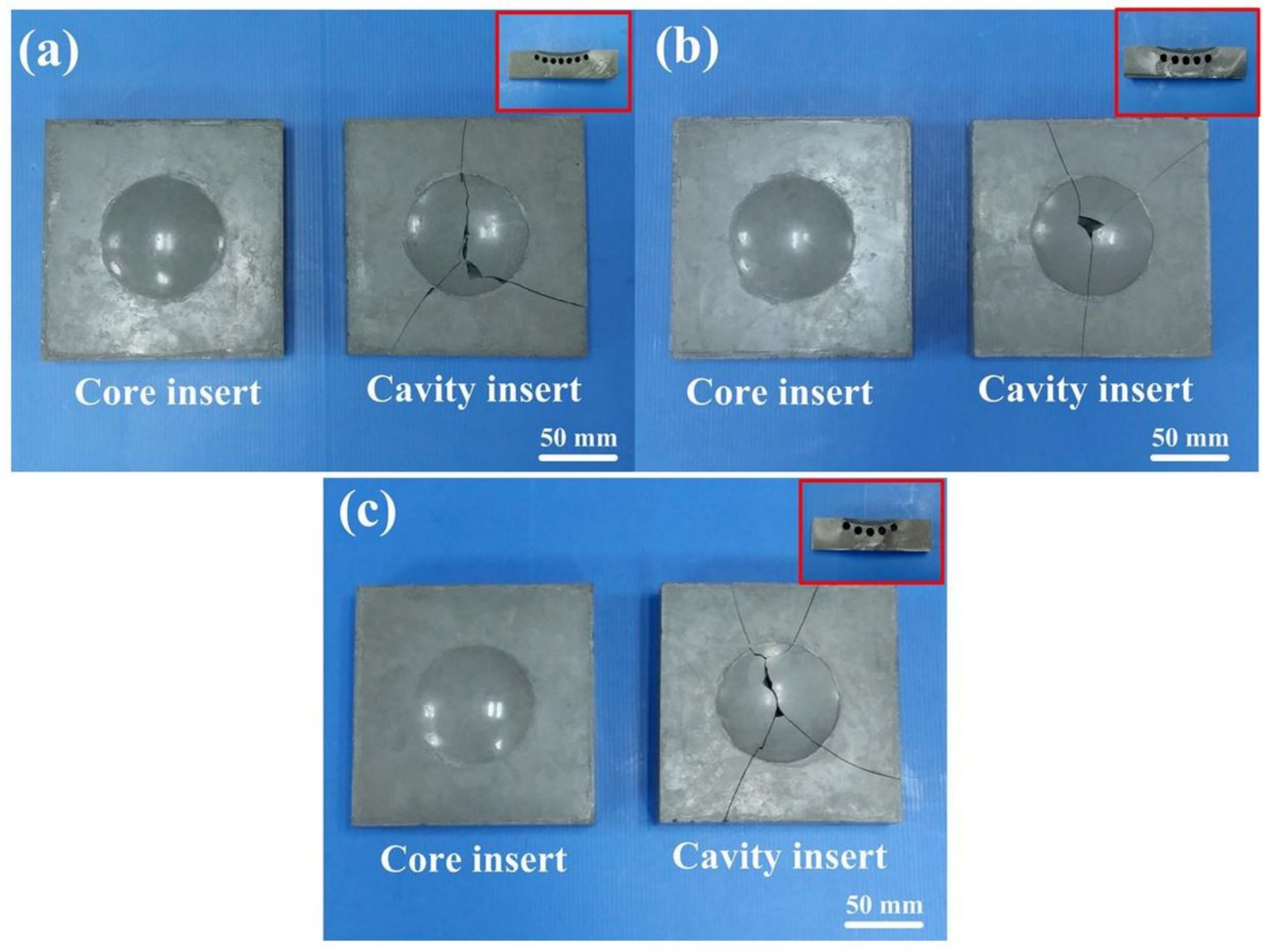

Figure 14

Breaking results of the injection molding tooling with diameters of (a) $8 \mathrm{~mm}$, (b) $9 \mathrm{~mm}$, and (c) $10 \mathrm{~mm}$ 


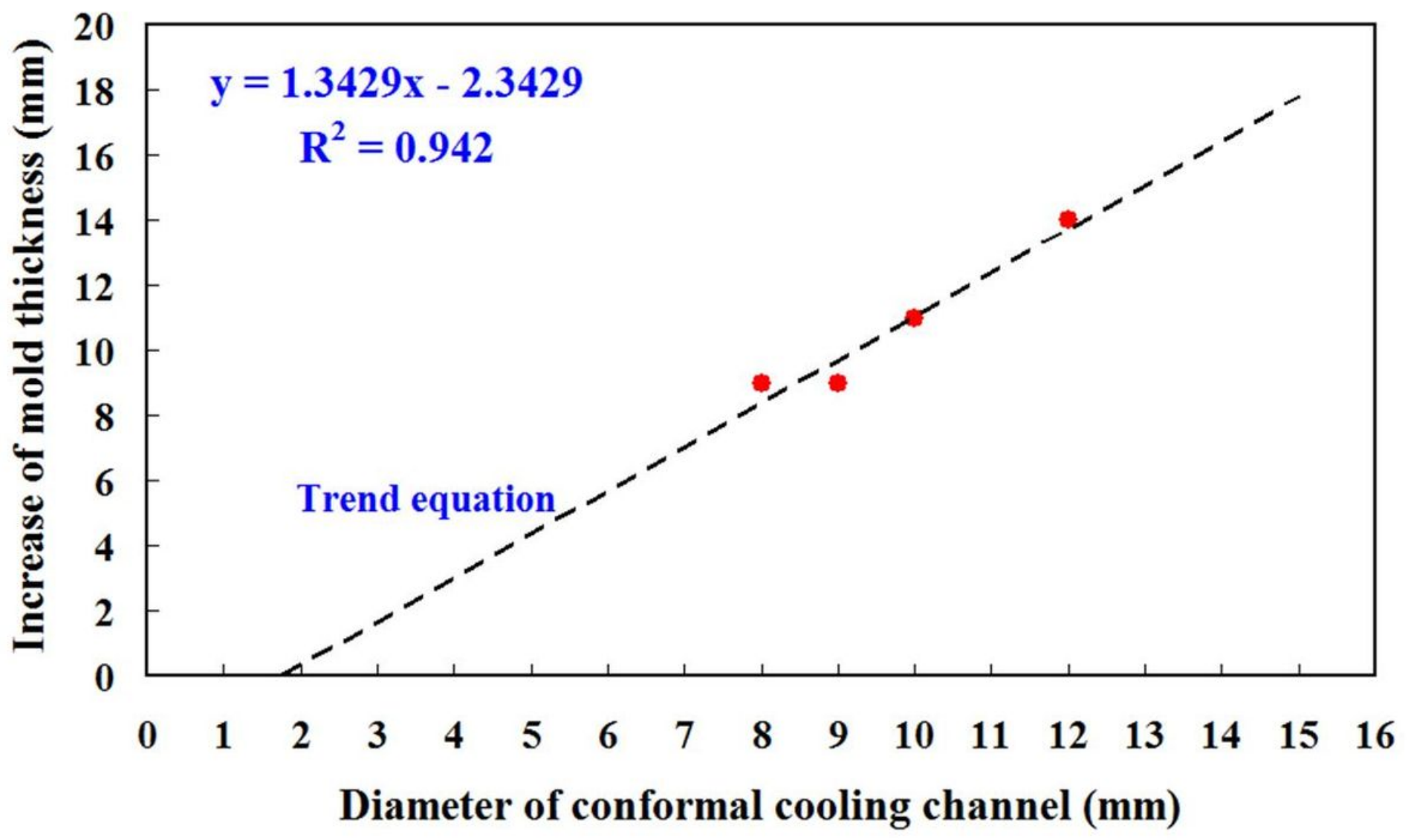

Figure 15

The amount of the increase in the mold thickness as a function of different diameters of cooling channels 